\title{
O ensino da leitura na Educação de Jovens e Adultos: da vida para a escola, da escola para a vida
}

Maria José Gomes Cavalcante ${ }^{1}$

Eliana Borges Correia Albuquerque ${ }^{2}$

\section{Resumo}

A presente pesquisa teve o objetivo de investigar as práticas de ensino da leitura de uma professora da $2^{a}$ Fase da Educação de Jovens e Adultos (EJA) e as possíveis relações existentes entre o ensino promovido por ela e as práticas de leitura vivenciadas por seus alunos fora da escola. Participaram uma professora e seus 11 alunos da rede pública de ensino de Garanhuns (PE). Os resultados evidenciaram que os eventos de letramentos propostos pela professora estavam "mais próximos" da prática social da leitura, uma vez que nestes era promovido o contato e o estudo de diferentes gêneros textuais, o trabalho efetivo com estratégias de leitura e, principalmente, as experiências dos alunos eram consideradas no processo de construção da compreensão dos textos trabalhados.

Palavras-chave: Educação de Jovens e Adultos; Ensino da Leitura; Gêneros Textuais; Letramento.

Reading teaching in Youth and Adult Education: from life to school, from school to life

\section{Abstract}

This research aimed to investigate the reading teaching practices of a teacher from the early years of Youth and Adult Education (EJA) and the possible relationships between the teaching promoted by her and the reading practices experienced by her students in extra-school contexts. A teacher and her 11 students from the public school in Garanhuns (PE) participated in the research. The results showed that the literacy events proposed by the teacher were "closer" to the social practice of reading, since in these it was promoted the contact and the study of different textual genres, the effective work with reading strategies and, mainly, the students' experiences were considered in the process of understanding the texts read.

Keywords: Youth and Adult Education; Reading teaching; Textual genres; Literacy.

\section{Introdução}

Muitas pesquisas que analisam as concepções e práticas de ensino de professores na área de Língua Portuguesa vêm sendo desenvolvidas no Brasil, porém a maioria delas é voltada para a educação de crianças, o que faz do ensino e da aprendizagem da leitura e da escrita, em turmas da Educação de Jovens e Adultos (EJA), um campo ainda vasto a ser pesquisado. São poucos e incipientes os estudos que buscam se debruçar sobre os processos de ensino e de aprendizagem da leitura e da escrita de estudantes desta modalidade de ensino, principalmente no que diz

\footnotetext{
${ }^{1}$ Universidade Federal do Agreste de Pernambuco, Garanhuns, maria-jose.cavalcante@ufape.edu.br ${ }^{2}$ Universidade Federal de Pernambuco, Recife, eliana.albuquerque@ufpe.com
} 
respeito à relação entre alfabetização e letramento. Tem-se avaliado muito e pesquisado pouco sobre os níveis de alfabetização e letramento da população adulta (SOARES, 2010).

Ao longo da história da educação no Brasil, podemos perceber claramente como se constituiu, no decorrer dos anos, o grande contingente de pessoas analfabetas. Ainda no período colonial foi desenvolvida uma ação educativa missionária pelos jesuítas cujo objetivo era ganhar adeptos ao cristianismo e subjugar a população indígena e escrava aos colonizadores da época. Com o advento da República, as mobilizações em torno da erradicação do analfabetismo, visto como uma vergonha nacional, foram iniciadas. Passou-se a investir em programas de alfabetização e educação escolar, apoiados no princípio da democratização de oportunidades de escolarização básica dos jovens e adultos.

No final do século passado, mais especificamente em meados da década de 1980, surgiu no Brasil a discussão sobre um fenômeno denominado de "letramento", relacionado ao uso social da leitura e da escrita. Além disso, novas perspectivas no ensino-aprendizagem da leitura e da escrita passaram a ser discutidas e consideradas, advindas de estudos e pesquisas desenvolvidos em diferentes áreas (Psicologia, Educação, Linguística, dentre outras). Percebeuse que era preciso pensar a leitura não como códigos a serem decifrados, mas como um objeto de conhecimento a ser construído, que requer do indivíduo o engajamento e a mobilização de vários conhecimentos (KLEIMAN, 1999). Percebeu-se, ainda, que era preciso fazer a leitura funcionar como interação, como interlocução na sala de aula, como um processo de interação entre o leitor e o autor mediado pelo texto, experienciando, desse modo, a linguagem nas suas várias possibilidades.

É neste contexto de expansão das oportunidades educacionais aos jovens e adultos e de inovações teóricas, que foi criado o Indicador Nacional de Alfabetismo Funcional - INAF (2000), com o objetivo de apurar as habilidade e práticas de leitura e escrita da população de jovens e adultos em geral - quinze a 64 anos - independentemente do nível de escolaridade. Como apontado por Lima, Batista e Ribeiro (2015), após uma década de realização de pesquisas (20012011), o panorama dos resultados do INAF - 2011 mostra que em relação ao "efeito da escolaridade", mais da metade das pessoas que chegaram a completar as séries iniciais do ensino fundamental podem ser consideradas analfabetas funcionais, $48 \%$ dos indivíduos superam a barreira do analfabetismo funcional, e apenas $5 \%$ destes chegam a atingir o nível pleno. Em 
contrapartida, os dados obtidos também apontam, segundo os referidos autores, que mesmo dentre os jovens e adultos sem nenhuma escolaridade, $47 \%$ já demonstraram algum domínio de habilidades iniciais, permitindo que superem o nível de analfabetismo absoluto.

Tais resultados apontam para a necessidade de repensar o ensino da leitura que está sendo realizado em salas de aula da EJA, uma vez que eles revelam que regressar à escola e nela permanecer não tem garantido aos jovens e adultos alcançarem o seu objetivo de aprender ler e escrever e, autonomamente, inserir-se em práticas sociais de leitura e escrita, apesar de já chegarem à escola com um determinado nível de letramento, como foi comprovado na pesquisa do INAF/ 2011.

É, pois, no âmbito desta problemática que se inseriu nossa pesquisa de doutorado que teve como objetivo geral, investigar as práticas de ensino da leitura de duas professoras da $2^{\underline{a}}$ Fase da EJA e as possíveis relações existentes entre o ensino promovido por elas e as práticas de leitura vivenciadas por seus alunos no cotidiano. Tivemos como objetivos específicos, dentre outros, identificar as concepções de leitura que possuem as professoras investigadas e as relações dessas com as práticas de ensino da leitura propostas em sala de aula; e analisar os eventos de letramento relacionados à leitura propostos pelas professoras. Neste artigo, apresentaremos um recorte dos dados resultantes desta investigação, concluída em 2017, relacionados à prática de ensino da leitura de uma das professoras investigadas.

Adotamos uma abordagem metodológica qualitativa mais apropriada aos objetivos da pesquisa. Realizamos a coleta de dados em uma turma da EJA de uma escola da rede municipal de Garanhuns, Pernambuco (PE), e, para isso, utilizamos dos seguintes procedimentos: observações de aula da docente, nas quais registramos as ações desenvolvidas para o ensino da leitura pela professora em diferentes disciplinas; entrevista com a docente, antes e depois das observações; e também, entrevistas com seus alunos, após as observações.

\section{Letramento na Educação de Jovens e adultos}

O aparecimento deste termo letramento no Brasil está associado à superação do analfabetismo em uma sociedade que vem, progressivamente, valorizando a escrita e tem como foco de discussão o aspecto educacional e pedagógico deste fenômeno. Neste sentido, 
letramento designa as habilidades de leitura e escrita de crianças, jovens ou adultos, em práticas sociais que envolvem a língua escrita (SOARES, 2010).

Dentre as várias agências de letramento, a escola é considerada na sociedade atual a mais importante delas, pois a ela é atribuída a responsabilidade da inserção formal dos indivíduos no mundo da escrita, por meio da ação educativa que exerce (KLEIMAN, 1995). E, para dar conta de tal atribuição, ela redefiniu, ou melhor, reduziu o conceito de letramento, tornando-o um sistema de conhecimento descontextualizado, autônomo, e, por isso, insuficiente para responder às exigências das práticas sociais que envolvem a língua escrita fora da escola (SOARES, 2006).

Como apontado por Kleiman (1995), as práticas de letramento da escola se embasam no modelo de letramento autônomo. Segundo Street $(2014$, p.9),

[...] há quem aposte que o papel da escola moderna e das políticas públicas seria justamente desenvolver este 'letramento' - um conjunto de competências, visto que o sujeito escolarizado teria que possuir capacidade para usá-lo. As instituições, o texto, os sujeitos são tratados de forma homogênea, independente do contexto social.

No caso de tais práticas ocorrerem no âmbito da EJA, os conhecimentos dos alunos advindos das práticas sociais não serão considerados no processo de ensino, uma vez que a cultura, a forma de expressão oral, as experiências de letramento social dos mesmos são vistas como inferiores ou mesmo como marginais, sendo necessário que sejam substituídas por outras práticas aceitas e valorizadas pela escola. Em consequência, a "aprendizagem" ocorrerá sem significado, com sentido apenas instrumental.

Street (2013) afirma que o letramento varia de um contexto para o outro, de uma cultura para outra, de acordo com as identidades, as relações sociais e culturais e, assim, consequentemente, variam os efeitos dos diferentes letramentos em diferentes condições. Ao se privilegiar apenas uma variedade de letramento, se desconsidera as outras, como ocorre no modelo autônomo de letramento.

Discutindo sobre letramento e alfabetização de adultos, Kleiman (1995) apresenta uma pesquisa por ela realizada sobre "a interação na aula de alfabetização de adultos, focando a potencialidade de transformação da concepção de letramento dominante nesses contextos" 
(p.48). Ela analisa alguns fragmentos das aulas observadas, tece algumas considerações a partir de três categorias de análise:

(1) Em relação às Práticas Discursivas em conflito: a construção de funções não complementares, a autora afirma que a interação na aula de alfabetização de adolescentes e adultos é potencialmente conflitiva, pois nela se visa ao deslocamento e substituição das práticas discursivas do aluno por outras práticas, da sociedade dominante. Ao mesmo tempo em que a aquisição das novas práticas é percebida como necessária para sobrevivência e mobilidade, se constitui no prenúncio do abandono das práticas discursivas familiares.

(2) No tocante à Identidade em conflito: a (re)construção de um sujeito menor, Kleiman (1995) afirma que um dos pressupostos mais prevalentes, populares e duradouros do letramento autônomo é o das consequências cognitivas da alfabetização, independentemente dos contextos e práticas de escrita. A discussão aberta (entre professor e alunos) do postulado conduziria à desnaturalização da ideologia do modelo autônomo subjacente à prática escolar.

(3) Em relação aos Valores em conflito: a resistência à cultura letrada, Kleiman coloca que o conflito constitutivo da comunicação entre professor e aluno na aula pode vir a ser o elemento transformador quando as práticas dominantes são examinadas a fim de desnaturalizar os pressupostos do modelo de letramento dominante, o modelo autônomo. Somente quando essa prática discursiva for adotada é que se pode pensar na construção de contextos de aprendizagem.

A partir das considerações apresentadas, Kleiman (1995) propõe que sejam conhecidas as práticas de letramento de grupos não-escolarizados e sugere a adoção da perspectiva ideológica do letramento tendo em vista a elaboração de uma pedagogia culturalmente relevante e crítica.

Este segundo modelo de letramento, denominado de ideológico, de acordo com Street $(2003, p .4)$

oferece uma visão com maior sensibilidade cultural das práticas de letramento, na medida em que elas variam de um contexto para outro. Esse modelo parte de premissas diferentes das adotadas pelo modelo autônomo - propondo por outro lado que o letramento é uma prática de cunho social, e não meramente uma habilidade técnica e neutra, e que aparece sempre envolto em princípios epistemológicos socialmente construídos. 
Concordamos com a autora de que a inserção dos jovens e adultos não-alfabetizados e com pouca escolaridade na escola deve se dar em consonância com a formação histórica e social desses sujeitos, ou seja, na perspectiva do modelo ideológico do letramento. Nesse sentido, defendemos que uma das tarefas mais importantes da educação é a de propiciar as condições para que os alunos possam assumir a sua própria identidade cultural enquanto ser social, histórico, como ser pensante, comunicante, transformador da sua realidade (FREIRE, 1996).

\section{O ensino da leitura na EJA: para além da sala de aula}

A partir de meados dos anos 1980, com o avanço das pesquisas e estudos provenientes da área das Ciências Linguísticas e por questões de natureza sociopolítica, a concepção de língua passou a sofrer alterações, culminando na difusão de uma nova abordagem: a língua enquanto processo de interação. Considerada como fruto de um processo histórico e sociocultural, que varia de acordo com a época e com a situação em que é produzida, a língua passou a ser considerada como uma atividade dialógica, ideológica e sócio-histórica (BAKHTIN, 2003; ORLANDI, 2001).

Conceber a língua como um processo dialógico-interativo e considerar a sua função comunicativa trouxe implicações pedagógicas e alterou, em sua essência, a concepção de leitura, que passou a ser vista como uma atividade interativa, altamente complexa, de produção de sentidos (KOCH, 2002). Compreendeu-se, assim, que ler não é decifrar, como num jogo de adivinhações, o sentido de um texto, mas que ler é

Partir de um texto, ser capaz de atribuir-Ihe significação, conseguir relacioná-lo a todos os outros textos significativos para cada um, reconhecer nele o tipo de leituras que o seu autor pretendia e, dono da própria vontade, entrega-se a esta leitura, ou rebelar-se contra ela, propondo outra não prevista (LAJOLO, 2009, p.101).

Concordamos com Lajolo quando ela aponta que a construção do sentido do texto pelo leitor não se constitui em uma réplica ou tradução do significado que o autor quis dar. Esta construção se realiza, evidentemente, com base nos elementos linguísticos presentes na superfície textual e na sua forma de organização e requer a mobilização de um vasto conjunto 
de saberes, múltiplas habilidades e processos cognitivos.

Discorrendo sobre os aspectos cognitivos da leitura, Kleiman (1999, p.13) afirma que "a compreensão de um texto é um processo que se caracteriza pela utilização de conhecimentos prévios: o leitor utiliza na leitura o que ele já sabe, o conhecimento adquirido ao longo de sua vida". Este conhecimento é constituído pelo conhecimento linguístico, que abrange os conhecimentos de cunho gramatical, lexical e semântico; o conhecimento textual, que envolve um conjunto de noções e conceitos sobre o texto. Quanto mais conhecimento linguístico e textual o leitor tiver, mais fácil será sua compreensão. Relacionado a estes conhecimentos, encontra-se o conhecimento de mundo: o que é adquirido por meio de práticas de interação cultural e social vivenciadas pelo leitor.

Kleiman (1999) ressalta que é o conhecimento prévio que possibilita ao leitor fazer as inferências necessárias para relacionar diferentes partes discretas do texto, num todo coerente, ao permitir que o leitor "resgate" informações que não estão explicitamente apresentadas no texto. Logo, a ausência desse conhecimento impossibilitará a compreensão, pois como afirmam Chartier, Clesse e Hérbrard (1996), "ninguém pode compreender as situações evocadas nos livros se elas forem totalmente estranhas à sua experiencia e seus conhecimentos ou exteriores a seu meio" (p.115).

Partindo destas concepções, somos levados a indagar: como tem ocorrido o ensino da compreensão leitora nas escolas e, mais especificamente, na EJA?

Com o surgimento do fenômeno do letramento no Brasil, o trabalho com gêneros textuais passou a ter prioridade na escola com o objetivo de inserir os alunos em práticas sociais de leitura e da escrita. É fundamental propor trabalhos com os diferentes gêneros que circulam na sociedade, mas sem deixar de criar situações que permitam aos alunos desenvolverem as diferentes capacidades envolvidas no ato de ler.

Nesta perspectiva, estudos como os de Marinho, Silva e Morais (2009); Porto (2011); e Solé (2008) têm demonstrado que o desenvolvimento da compreensão de leitura se dá pelo ensino de estratégias de leitura. Para tal, se faz necessário um trabalho sistemático e regular do professor envolvendo tais estratégias.

De acordo com Solé (2008, p.69-70), "as estratégias de compreensão leitora são procedimentos de caráter elevado, que envolvem a presença de objetivos a serem realizados, o 
planejamento das ações que desencadeiam para atingi-los, assim como sua avaliação e possível mudança". Elas podem ser trabalhadas pelos educadores antes, durante e depois da leitura do texto. Segundo a autora, constituem as estratégias de compreensão leitora para:

(1) Antes da leitura: antecipação do tema ou ideia principal a partir de elementos paratextuais (como: título, subtítulo, do exame de imagens, de saliências gráficas, dentre outros); levantamento do conhecimento prévio sobre o assunto; expectativas em função do suporte; expectativas em função da formatação do gênero; dentre outras.

(2) Durante a leitura: confirmação, rejeição ou retificação das antecipações ou expectativas criadas antes da leitura; localização ou construção do tema ou da ideia principal; esclarecimentos de palavras desconhecidas a partir da inferência ou consulta do dicionário; formulação de hipóteses a respeito da sequência do enredo; construção do sentido global do texto; Identificação das pistas que mostram a posição do autor; dentre outras.

(3) Depois da leitura: construção da síntese semântica do texto; utilização do registro escrito para melhor compreensão; troca de impressões a respeito do texto lido; relação de informações para tirar conclusões; avaliação das informações ou opiniões emitidas no texto; avaliação crítica do texto.

A autonomia do aluno no uso dessas estratégias implica em sua autonomia enquanto leitor. Corroborando na discussão desta temática, Brandão e Rosa (2010) destacam a importância das situações de conversa sobre textos em sala de aula para a formação de leitores, pois defendem que esta é uma forma de ensino da compreensão, e a necessidade de planejamento de tais situações, a fim de que as perguntas propostas na conversa com os alunos levem à reflexão crítica sobre o texto, o que contribuiria para a ampliação do significado do que foi lido.

Alguns estudos (MARINHO; SILVA; MORAIS, 2009; MOURA, 2001; PORTO, 2011) analisaram práticas de ensino de compreensão leitora e revelaram que as práticas ora se aproximam de ensino mais explicito da compreensão, por oportunizarem aos educandos as ajudas necessárias à compreensão do texto, bem como por promoverem a elaboração de estratégias de leitura; ora as práticas focam a leitura como um suporte para trabalhar o ensino de ortografia ou da gramática, a produção textual, sem priorizar a compreensão do texto.

Ainda que muitos avanços tenham ocorrido no tratamento dado à leitura na escola, o 
ensino da compreensão é algo ainda geralmente esquecido na mesma, o que tem gerando um grande número de alunos com dificuldade de entender o que leem, mesmo quando estes já sabem ler (BRANDÃO; ROSA, 2010).

\section{Metodologia}

Segundo Teis e Teis (2006, p.1), a abordagem qualitativa de pesquisa "tem se firmado como promissora possibilidade de investigação em pesquisas realizadas na área da educação", por se caracterizar pelo viés interpretativo dos dados e não pela mensuração dos mesmos.

Tomando tal aspecto como ponto de partida para escolha e ao aprofundarmos o nosso olhar sobre algumas outras características da pesquisa qualitativa, viemos a confirmar nossa opção. São elas: (1) A pesquisa qualitativa, por ser uma abordagem "naturalista" de pesquisa, “não envolve manipulação de variáveis, nem tratamento experimental; é o estudo do fenômeno em seu acontecer natural" (ANDRÉ, 1995, p.17); (2) considera-se, assim, que cada sujeito a ser investigado tem concepções próprias sobre a realidade e o cotidiano que fabrica. Segundo Chizzotti (2006, p.69), pesquisas dessa natureza,

[...] dedicam-se à análise dos significados que os indivíduos dão às suas ações, no meio ecológico em que constroem suas vidas e suas relações, à compreensão do sentido dos atos e das decisões dos atores sociais ou, então, dos vínculos indissociáveis das ações particulares com o contexto social em que estas se dão.

Teis e Teis $(2006$, p.5) afirmam, ainda, que é preciso mergulhar na realidade cotidiana da escola, pois é esse "cotidiano que se revela como um espaço de confrontos e interesses entre um sistema oficial [...] e outro, o dos sujeitos - alunos, professores, funcionários - que não são apenas agentes passivos diante da estrutura".

Assim, neste estudo, mergulhamos no cotidiano de uma turma da EJA de uma escola da rede pública do município de Garanhuns/PE. Para tal, realizamos os seguintes procedimentos metodológicos:

(1) Observações das aulas: acompanhamos e registramos as ações desenvolvidas para o ensino da leitura pela professora, no período de maio a outubro de 2015, totalizando 16 dias de 
observação. As observações eram semanais e as aulas eram gravadas para, posteriormente, serem transcritas.

(2) Entrevistas semiestruturadas: indagamos e registramos as vozes dos sujeitos (professora e seus alunos) sobre vários aspectos que julgamos essenciais para atingir o objetivo da pesquisa. Especificamente para a professora, indagamos sobre a sua experiência docente, o perfil de sua turma, o planejamento das aulas, a rotina de sua sala de aula e as práticas de ensino da leitura.

A professora Ana era graduada em Pedagogia, 2001, e iniciou sua formação profissional quando fez o curso de Magistério em 1993. Após o termino da graduação, ela fez especialização em Gestão de Recursos Humanos e, posteriormente, em Psicopedagogia.

Quando entrevistada, a docente relatou que tinha 22 anos de trajetória profissional, sendo cinco na EJA e que já havia lecionado nesta modalidade em uma escola da zona rural. Na época, a professora trabalhava nos três expedientes, em cada horário com um grupo de alunos específicos: manhã, na Educação Infantil; à tarde, no 5o ano do Ensino Fundamental; e, à noite, na Fase II da EJA.

Com um grupo classe formando por 14 alunos, a professora Ana nos informou que a turma inicialmente era composta por 25 alunos, mas muitos deles nunca haviam comparecido às aulas. Durante o período de observação, a turma apresentou uma frequência flutuante, e alguns dos alunos (especialmente os adolescentes) quase não compareciam às aulas.

Dos alunos que formavam a turma, entrevistamos 11 deles, os mais frequentes às aulas. Dos entrevistados da turma: duas eram adolescentes, duas eram jovens e sete eram adultos. Uma turma com grande heterogeneidade etária por ser composta por estudantes na faixa dos 15 aos 52 anos de idade e com a presença marcante das mulheres.

Estudantes com experiências e saberes distintos, advindos da prática social e profissional, pois exerciam diferentes profissões (vendedoras, empregadas domésticas, babá, pedreiros, agricultora, dentre outras) e possuíam uma experiência com escola na infância marcada pela exclusão. A grande expectativa dos estudantes ao retornarem à escola era de aprender a ler e a escrever objetivando a conquista da autonomia (tão sonhada) e assim vivenciarem novas experiências de letramento. 


\section{Resultados e discussão}

Antes de falarmos especificamente sobre os eventos de letramento envolvendo a leitura de textos realizados na sala de aula da professora Ana, apresentaremos um pouco da sua rotina.

Diariamente, ao chegar na escola, a professora Ana se já dirigia para a classe, onde seus alunos a aguardavam. Ao entrar na sala, normalmente às 19h, ela cumprimentava seus alunos e, enquanto conversava de forma descontraída com eles, selecionava os livros e outros materiais que iriam ser usados na aula. Dando início à aula, Ana realizava regularmente uma oração ou/e a leitura de um pequeno texto e fazia uma breve reflexão. Em seguida, ela propunha a próxima atividade que, geralmente, era a leitura de outro(s) texto(s) com o objetivo de realizar o ensino de um novo conteúdo ou o trabalho com compreensão leitora.

Por volta das 20h10, os alunos eram liberados para a merenda servida no pátio da escola. Neste intervalo, a docente se dirigia para a sala dos professores, onde se encontrava com seus colegas e demais funcionários. De volta à sala de aula, aproximadamente às $20 \mathrm{~h} 30$, a professora procedia à finalização da atividade iniciada antes da merenda, corrigindo-a para em seguida fazer nova atividade ou propor a leitura de outro texto, geralmente com a mesma temática ou relacionada ao(s) lido(s) e trabalhado(s) no primeiro período da aula (antes do intervalo).

A observação da rotina desenvolvida pela Professora Ana nos possibilitou compreender melhor o trabalho de ensino da leitura desenvolvido pela mesma, bem como identificar as diferentes maneiras que ela estruturava os eventos de letramentos vivenciados em suas aulas.

A partir das descrições e análise das ações realizadas nas aulas observadas, verificamos que foram vivenciados 44 eventos de letramento na turma: 25 deles tiveram como foco o ensino da Língua Portuguesa, com foco no trabalho com o eixo da leitura. Além destes, verificamos, também, 5 eventos voltados para o ensino da Matemática, 3 para o ensino das Ciências da Natureza, 3 eventos interdisciplinares e, ainda, 8 eventos em que se priorizou a leitura como reflexão/deleite. Todos os eventos foram realizados na sala de aula, em horário normal (19h às 22h).

Para descrevermos e analisarmos os 44 eventos, os organizamos em quatro tipos, considerando os objetivos da leitura, o material lido, a sequência de ações realizadas durante o evento, entre outros aspectos. Apresentaremos, a seguir, uma tabela com os tipos de evento e suas frequências.

Periódico Horizontes - USF - Itatiba, SP - Brasil - e020065 
Tabela 1: Tipos de eventos de letramento observados nas 16 aulas da Professora Ana

\begin{tabular}{|l|c|}
\hline \multicolumn{1}{|c|}{ CATEGORIAS DE EVENTO } & FREQUÊNCIA \\
\hline Ler/escutar textos para reflexão e/ou para deleite & 8 \\
\hline Ler/caracterizar diferentes gêneros textuais & 17 \\
\hline Ler para ensinar/aprender um conteúdo & 11 \\
\hline Ler/realizar atividades para retomada de conteúdo. & 8 \\
\hline
\end{tabular}

Fonte: os autores

Dando continuidade à análise, descreveremos detalhadamente um evento da categoria ler/caracterizar diferentes gêneros textuais pois, como podemos verificar na Tabela 1, a professora realizou 17 vezes este tipo de evento durante as 16 aulas observadas, demonstrando ser a leitura um dos focos de atenção de seu ensino. Tal foco certamente visa atender a uma das principais expectativas de seus alunos que era a de participar autonomamente de eventos envolvendo a leitura e a escrita fora da escola.

\section{Ler/caracterizar diferentes gêneros textuais}

Nas 17 vezes em que trabalhou a compreensão leitora, a docente leu textos autênticos e didáticos extraídos de várias fontes (livro didático, internet, revistas etc.), quase diariamente, visando a construção de sentido do texto, uma ou duas vezes na aula. Isto se dava por meio da exploração de estratégias orais ou/e por meio de uma atividade escrita. Trabalhava também o gênero, geralmente, propondo a leitura de um texto didático e explorando o conhecimento dos alunos a respeito dele, antes ou depois da leitura.

Quando indagamos à professora sobre seu o trabalho com a leitura, ela nos respondeu ser este um dos seus principais eixos de ensino e nos justificou:

Quero que meu aluno aprenda a ler, porque o desejo de cem por cento é aprender a ler ou melhorar a leitura. Que essa leitura leve ele a algum lugar, para uns vai ser para faculdade, para outros é para ler qualquer texto. Esse éo objetivo deles e o meu é esse também, de fazer com que os alunos consigam o objetivo deles, que é de entender o que está escrito em qualquer lugar. 
Podemos perceber em sua resposta, que a professora conhece as expectativas de seus alunos em relação à leitura e busca atendê-las, bem como demonstra ter consciência de que o trabalho com compreensão leitora é fundamental para seus alunos se tornarem leitores autônomos, capazes de entender "o que está escrito em qualquer lugar", como ela mesma afirmou. Coerentemente com sua afirmação, observamos nas aulas que Ana buscava colocar seus alunos em contato com uma diversidade de textos. Como apontado por Kleiman (1999, p.20),

Quanto mais conhecimento textual o leitor tiver, quanto maior sua exposição a todo tipo de texto mais fácil será sua compreensão, pois o conhecimento de estruturas textuais e de tipos de discurso determinará, em grande medida, suas expectativas em relação aos textos, expectativas estas que exercem um papel considerável na compreensão.

Como exemplo da prática de ensino da compreensão realizado pela docente, no Quadro 1, apresentaremos as ações realizadas pela professora em um evento de leitura de um poema realizado na 4a aula observada, seguido da descrição de cada ação.

Quadro 1: Ações realizadas no evento de leitura de poema

\begin{tabular}{|c|c|c|}
\hline MATERIAL ESCRITO & FONTE & SÍNTESE DAS AÇÕES \\
\hline $\begin{array}{l}\text { Poema: Procura-se } \\
\text { (Roseana Murray) }\end{array}$ & $\begin{array}{l}\text { Internet: } \\
\text { https://www.pensador.com/frase } \\
\text { /MTg0ОTY4MQ/ }\end{array}$ & $\begin{array}{l}\text { 1.Cópia do poema } \\
\text { 2.Leitura do texto pela professora } \\
\text { 3. Exploração de estratégias de leitura } \\
\text { (oral) } \\
\text { 4. Apresentação de algumas } \\
\text { características do gênero poema. }\end{array}$ \\
\hline
\end{tabular}

Fonte: os autores

Ao chegar na sala de aula, a professora cumprimentou os alunos presentes, fez a oração do "Pai Nosso" e, em seguida, solicitou que os alunos copiassem o texto que ela iria escrever no quadro. 


\begin{tabular}{|c|}
\hline PROCURA-SE \\
Roseana Murray \\
Procura-se algum lugar no planeta \\
Onde a vida seja sempre uma festa \\
Onde o homem não mate \\
Nem bicho, nem homem \\
E deixe em paz \\
As árvores da floresta
\end{tabular}

Após a cópia do texto pelos alunos, a professora comentou sobre a aula do dia anterior e realizou a leitura do texto.

Professora: Lembram que, ontem, nós falamos sobre preservação de meio ambiente, de consciência ecológica, sobre a necessidade de preservação das matas, das florestas, da fauna, da flora. Este texto está relacionado com isso que nós trabalhamos, ontem. Esse texto é um poema bem pequenininho, que diz assim...

(A professora faz a leitura do texto)

P: Agora, vamos ler todos!

(Alunos e professora leem novamente o texto).

Em seguida, a professora passou a trabalhar a compreensão do texto, lançando algumas questões orais para turma.

P: Por que a autora usa este título "Procura-se"? O que vocês acham?

Aluno 1: Está procurando um lugar no planeta...

$\mathrm{P}$ : Isso. Ai, ela faz como um anúncio. Quando a gente faz uma placa de uma casa que a gente quer se desfazer dela, o que a gente bota no anuncio ou numa placa?

Alunos: Vende-se.

P: Vende-se uma casa. Se for um carro?

Aluno 2: Vende-se um carro.

P: Se não, num classificado de um jornal, quando você quer encontrar alguma coisa, quer 
comprar uma casa, como se coloca no jornal?

Aluno 2: Procura-se uma casa!

P: Procura-se uma casa e se descreve as características da casa. Ou procura-se um carro, descreve a cor, a marca, modelo, o ano do carro. Ela usou esse mesmo tipo de escrita, aí, ela vai colocar lá no título do texto "Procura-se". Ela está procurando um lugar, que talvez nem exista. Como é esse lugar?

Alunos: A vida é uma festa, os homens não matem o outro.

P: Como está o lugar que a gente vive? Como está o nosso planeta, nosso mundo?

Aluno 1: Destruído!

P: E quem está destruindo este mundo?

Aluno 2: O próprio homem!

P: E o que acontece no nosso mundo que está sendo destruído?

Aluno 3: Desmatamento.

Aluno 2: Assassinato.

Aluna 4: Poluição, sujeira nos rios, nas ruas...

Aluno 1: Roubo, corrupção.

(Um aluno comenta sobre uma notícia apresentada no Fantástico)

P: E qual é o nome do nosso planeta?

Alunos: Terra

P: E no nosso planeta, a vida é sempre uma festa?

Alunos: Não!

Aluna 2: É uma dureza viver neste mundo, tem de ter cuidado com a vida, se não morre rapidinho.

P: A gente pode tentar sempre fazer o melhor, mas... É um lugar onde não existe assassinato? Alunos: Não!

P: Dá até desgosto de assistir repórter. Se você assistir o NE TV de meio dia, das dez reportagens que tiver, oito ou sete é só assassinato, morte no trânsito.

Aluno 1: Violência, só violência. A gente fica é com medo de sair de casa.

P: "Onde não se matem bicho". Também não existe isto em nosso planeta?

Aluno: Se mata e muito bichos!

Periódico Horizontes - USF - Itatiba, SP - Brasil - e020065 
P: Se mata pra quê?

Aluno1: Pra alimento.

P: Mas, só para alimento?

Aluna 5: E por maldade! Pra ganhar dinheiro, também!

P: Outro dia também no Fantástico eu vi uma reportagem [...] do guarda florestal que atirou... Aluno 6: O guarda... (O aluno conta a notícia)

P: E aí, vejam, "E que deixem em paz as árvores nas florestas". É isso que a gente viu? Ontem, a gente estudou a história de quem?

Alunos: Chico Mendes

P: E ele morreu por quê?

Aluno 1: Porque estava defendendo a natureza. O homem está destruindo as florestas, desmatando, queimando. E isto influencia no aquecimento global, a mudança de clima.

Professora: Isso mesmo, como a gente tem visto! A escassez de chuva. Garanhuns, mesmo, está muito quente.

Aluna 2: E como! Antigamente, fazia muito mais frio. Em julho, dava oito graus. Vê o calor que está hoje!

P: E a autora, termina como? Ela diz: "Onde o homem não mate homem". Então, realmente este título tem muito a ver. É bem coerente. "Procura-se". E vocês acham que ela vai achar um lugar assim? (A professora lê novamente o texto).

Alunos: Não!

Aluna 5: Muito difícil, o mundo está muito ruim. Todo canto é violência. Aqui mesmo, em Garanhuns, nem era tanta violência, mas agora está!

P: Talvez, gente, num lugar muito distante, que não tenha muita gente, que não tenha tanto convívio, talvez a gente ainda encontre um lugar que se aproxime deste que a autora está procurando. Mas, não é a nossa realidade, infelizmente. Este texto é para a gente refletir sobre tudo o que a gente vem comentando sobre a responsabilidade do homem sobre o meio ambiente, a natureza, a fauna, a flora.

Finalizando o trabalho com o texto, a professora fez um pequeno comentário sobre as 
características do gênero.

P: Como nós estávamos falando, esse texto lembra um anúncio. Mas, não é! Vou ler novamente o texto, ele é curtinho, e vocês prestem atenção à linguagem que a autora usa no texto. (A professora lê novamente o texto). O que vocês acham da linguagem, das palavras que ela escreveu o texto?

Aluna 5: Bonitas!

Aluno 1: Parece um poema!

P: Este texto é um poema. Cada linha dessa é um verso. Ele é curtinho, mas nos fala muita coisa com uma linguagem poética. Essa autora é conhecida e nós já lemos outros poemas dela aqui. Eu gosto muito [...].

Das ações descritas, queremos destacar que a professora explorou, principalmente, o conhecimento de mundo dos alunos para construir o sentido do texto. Incialmente, ela levantou questões envolvendo o título do texto ("Procura-se"), levando os alunos a buscarem referência nos anúncios de compra e venda de imóveis e carros de jornais e nas placas de "vende-se" colocadas nas frentes de casas, bastante familiares aos mesmos, visando que eles "captassem" a intenção da autora ao colocar tal título.

Em seguida, dando sequência ao trabalho de compreensão do poema, ela lançou várias questões que envolviam a comparação entre o lugar descrito no poema e a realidade do nosso planeta, objetivando que os alunos construíssem o sentido do texto a partir de sua própria visão de mundo e do conhecimento adquirido nas aulas anteriores sobre preservação ambiental (conteúdo que estava sendo trabalhado na disciplina de Ciências). Ana trabalhou estratégias envolvendo levantamento de hipótese, localização de informação, inferência, mas, principalmente, o conhecimento prévio do aluno.

Ao discutir o texto, a professora possibilitou a efetiva participação da turma, que expressou sua opinião, relatou situações relacionadas ao texto. Nesses momentos, pudemos perceber que Ana buscava levar os alunos a refletir, a "descobrir" que a leitura não se constituía apenas como códigos a serem decifrados, mas como objeto de conhecimento a ser construído, requer do leitor o engajamento de vários conhecimentos (KLEIMAN, 1999; KOCH, 2002; SOLÉ, 
2008).

Finalizando o trabalho com o texto, Ana fez alusão a algumas características do gênero: sua linguagem poética, sua organização em versos.

De forma geral, verificamos nas aulas que a professora priorizava alguns aspectos em sua prática, que consideramos importantes para que o trabalho realizado com a leitura assumisse um perspectiva interacionista, a saber: um trabalho com textos autênticos do interesse e apropriados aos alunos, envolvendo um leque de gêneros, em sua maioria, familiares a eles; um trabalho focando as caraterísticas e função social de cada gênero estudado e, principalmente, um trabalho embasado na leitura enquanto uma construção de sentido e o texto considerado o "lugar de interação" entre o autor e o leitor (KOCH, 2002, p.17),

Neste sentido, podemos afirmar que os objetivos de Ana para o ensino da leitura dialogam com o pensamento de vários teóricos (KLEIMAN, 1999; KOCH, 2002; LAJOLO, 2009) que afirmam que se faz necessário vivenciar/praticar a leitura como interação/interlocução na própria sala de aula e assim oportunizar aos alunos a experienciar em suas várias possibilidades. Além disso, podemos afirmar que as atividades de leitura que Ana desenvolvia com seus alunos estavam diretamente articulados com o seu objetivo "maior" que era o de seus alunos se tornarem leitores autônomos, independentes, capazes de usar a leitura em diversas situações fora da escola, por ser esta a expectativa da grande maioria de seus alunos.

Dessa forma, podemos perceber uma certa relação entre a proposta de ensino da leitura realizada pela professora e o modelo ideológico de letramento idealizado por Street (2014), uma vez que há uma preocupação da docente em propor leituras de textos de diferentes gêneros e que sejam do interesse dos seus alunos jovens e adultos, ainda que alguns deles sejam retirados de livros didáticos voltados para crianças.

Durante as aulas, verificamos que Ana frequentemente propunha a leitura relacionada às questões presentes no cotidiano de seus alunos, bem como buscava explorar várias estratégias de leitura e para isso utilizava-se prioritariamente das sequencias de atividades propostas nos livros didáticos adotados.

Quando entrevistada, Ana relatou sobre sua concepção de leitura, estando a mesma relacionada às discussões teóricas atuais que dialogam com a concepção de língua enquanto processo de interação (BAKHTIN, 2003). Ela afirmou: 
Ler não é só decodificar, como a gente aprendeu na nossa escola, é compreender o que está lendo. Entender o que está escrito e o que está subtendido. Exige pensar, elaborar. É como eu te falei, no início do ano, a primeira pergunta que eu fiz para eles (os alunos) na sala de aula e eles foram unanimes: ler! [...] Então, eles queriam ter a compreensão do que liam.

Em suas aulas, Ana propôs a leitura e estudo de vários gêneros, como: poema, tirinha, bilhete, fabula, notícia, texto informativo, receita, cartão postal, música, tabloide, dentre outros. $\mathrm{Na}$ entrevista, a professora afirmou que trabalhava todos os gêneros que considerava interessante para seus alunos e que um dos seus objetivos era mostrar para eles que a leitura era diversificada, envolvia um leque de diferentes opções e que o leitor escolhia de acordo com sua necessidade ou seu gosto.

\section{Considerações finais}

A partir dos resultados apresentados, podemos afirmar que a professora Ana priorizou, ao desenvolver o trabalho de compreensão leitora, o contato de seus alunos com uma diversidade de gêneros, que envolvia tanto os mais presentes no contexto escolar, como aqueles que circulam em contextos não-escolares. E, mesmo ao trabalhar o ensino de um conteúdo, ela colocava seus alunos em contato com uma variedade de gêneros, tanto de livros didáticos adotados (principalmente da EJA), como em seus suportes originais.

A exploração de estratégias pela docente possibilitava que os conhecimentos prévios dos leitores (alunos), relacionados a aspectos linguísticos e não-linguísticos, fossem explicitados. Ela demostrava compreender que era no diálogo entre o repertório prévio de experiências do leitor (conceituais, linguísticas, afetivas, atitudinais etc.) e o texto que se constitui a leitura/compreensão dele, bem como que é na socialização com outros leitores que se evoca os vários (possíveis) sentidos de um mesmo texto (KLEIMAN, 1999; KOCH, 2002; ORLANDI, 2001).

No tocante às relações entre as práticas leitura escolares e extraescolares dos seus alunos, elas se mostraram mais evidentes em função do trabalho de leitura que a professora realizava. Ela demonstrava reconhecer que as experiências de vida, inclusive a experiência leitora extraescolar de seus alunos, podiam contribuir para a aprendizagem dos vários conteúdos e 
também para que desenvolvessem a compreensão de textos, e que na mesma medida os conhecimentos adquiridos em sala de aula poderiam contribuir para que os alunos se inserissem em mais práticas de leitura no seu cotidiano. Percebíamos, em vários eventos de letramento realizados, que Ana buscava fazer o saber produzido em sala de aula circular não só neste âmbito, mas extrapolá-lo para além dos muros da escola. Inclusive, os alunos, quando entrevistados, destacaram em suas falas a socialização de conhecimentos, o espaço dado para expressar suas opiniões e saberes na sala de aula, bem como o estudo do gênero e o trabalho de leitura desenvolvido pela professora.

O conjunto de resultados obtidos no presente estudo indica ainda que podemos perceber alguns avanços no trabalho da leitura desenvolvido na sala de aula no sentido de abordá-la no contexto das práticas sociais, no que diz respeito ao acesso dos alunos aos gêneros que circulam na sociedade (especialmente àqueles que fazem parte do cotidiano dos mesmos), e ao estudo de suas funções e características sociais e a consideração do conhecimento do aluno na construção do sentido do texto. Consideramos que essas aproximações entre as práticas de leitura escolares e não-escolares se mostram, de alguma forma, ainda "tímidas" em razão da tensão existente entre práticas paradoxais. Como explica Lerner (2002), essa tensão é gerada a partir da responsabilidade social da escola de ensinar a ler e a escrever e do desafio que se põe, hoje, para esta instituição de "escolarizar" as práticas sociais da leitura e da escrita, preservando, porém, de alguma forma o seu sentido e propósitos sociais.

\section{Referências}

ANDRÉ, M. E. D. A. Etnografia da prática escolar. Campinas: Papirus, 1995.

BAKHTIN, M. Estética da criação verbal. São Paulo: Martins Fontes, 2003.

BRANDÃO, A. C. P.; ROSA, E. C. S. A leitura de textos literários na sala de aula: é conversando que a gente se entende. In: PAIVA, A.; MACIEL, F.; COSSON, R. (coords.). Literatura: ensino fundamental, vol. 20 [Coleção Explorando o Ensino], Brasília: MEC, SEB, 2010, p.69-88. Disponível em: http://portal.mec.gov.br/index.php?option=com_docman\&view=download\&alias=78412011-literatura-infantil-capa-pdf\&category_slug=abril-2011-pdf\&Itemid=30192. Acesso em: 11 jul. 2015.

CHARTIER, A. M.; CLESSE, C.; HERBRARD, J. Ler e escrever: entrando no mundo da escrita. Porto Alegre: Artmed, 1996.

Periódico Horizontes - USF - Itatiba, SP - Brasil - e020065 
CHIZZOTTI, A. Pesquisa qualitativa em ciências humanas e sociais. Petrópolis: Vozes, 2006.

FREIRE, P. Pedagogia da autonomia: saberes necessários à prática educativa. São Paulo: Paz e Terra, 1996.

KLEIMAN, A. B. Modelos de letramento e as práticas de alfabetização na escola. In: KLEIMAN, A. B. (org.). Os significados do letramento: uma perspectiva sobre a prática social da escrita. São Paulo: Mercado de Letras, 1995. p.15-61.

KLEIMAN, A. B. Texto e leitor: aspectos cognitivos da leitura. Campinas: Pontes, 1999.

KOCH, I. G. V. Desvendando os segredos do texto. São Paulo: Cortez, 2002.

LAJOLO, M. O texto não é pretexto: será que não é mesmo? In: ZILBERMAN, R.; RÖSING, T. (orgs.). Escola e leitura: velha crise, novas alternativas. São Paulo: Global, 2009, p.99 -112.

LERNER, D. Ler e escrever na escola: o real, o possível e o necessário. Porto Alegre: Artmed, 2002.

LIMA, Ana Lúcia, BATISTA Antônio Augusto G. e RIBEIRO, Vera Masagão. Apresentação. In. RIBEIRO, V. M., LIMA A. L. e BATISTA, A. A. G. (orgs.) Alfabetismo e Letramento no Brasil: 10 anos do INAF. Belo Horizonte: Autêntica, 2015, pp.11-20

MARINHO, A. L. S.; SILVA, J. R. P.; MORAIS, A. G. Ensino de compreensão leitora: práticas de ensino e propostas dos livros didáticos destinados à Educação de Jovens e Adultos (EJA). Trabalho de conclusão de curso (Graduação em Pedagogia) - Universidade Federal de Pernambuco, Recife, 2009, 33p.

MOURA, D. C. Por trás das letras: as concepções e práticas de ensino do sistema de notação alfabética na EJA. 2001. 166f. Dissertação (Mestrado em Educação) - Universidade Federal de Pernambuco, Recife, 2001.

ORLANDI, E. P. Discurso e leitura. 6. ed. São Paulo: Cortez, Editora da UNICAMP, 2001.

PORTO, C. C. R. F. Possíveis efeitos do ensino de compreensão de leitura em alunos do último ano do ensino fundamental I. 2011. 219f. Dissertação (Mestrado em Educação) - Universidade Federal de Pernambuco. Recife, 2011.

SOLÉ, I. Estratégias de leitura. Trad. Cláudia Schiling. 6. ed. Porto Alegre: Artmed, 2008.

SOARES, M. Letramento: um tema em três gêneros. Belo Horizonte: Autêntica, 2006. SOARES, M. Práticas de letramento e implicações para a pesquisa e para as políticas de alfabetização e letramento. In: MARINHO, M.; CARVALHO, T. C. Cultura escrita e letramento.

Periódico Horizontes - USF - Itatiba, SP - Brasil - e020065 
Belo Horizonte: Ed. UFMG, 2010, p.54-67.

STREET, B. V. Abordagens alternativas ao letramento e desenvolvimento. In: Teleconferência UNESCO Brasil sobre letramento e diversidade, 2003. Disponível em: http://telecongresso.sesi.org.br/templates/heard/index.php?language=pt\&modo=biblioteca\&a $\mathrm{ct}=$ categoria\&cdcategoria=22. Acesso em: 02 ago. 2017.

STREET, B. V. Políticas e práticas de letramento na Inglaterra: uma perspectiva de letramentos sociais como base para uma comparação com o Brasil. Caderno Cedes, Campinas, v.33, n.89, p.51-71, jan.-abr. 2013. Disponível em: http://www.scielo.br/pdf/ccedes/v33n89/a04v33n89.pdf. Acesso em: 06 jul. 2017.

STREET, B. V. Letramentos sociais: abordagens críticas do letramento no desenvolvimento, na etnografia e na educação. Trad. Marcos Bagno. São Paulo: Parábola Editorial, 2014.

TEIS, D. T.; TEIS, M. A. A abordagem qualitativa: a leitura no campo de pesquisa. 2006. Disponível em: http://www.bocc.ubi.pt/pag/teis-denize-abordagem-qualitativa.pdf. Acesso em: 14 ago. 2012.

Recebido em fevereiro 2020.

Aprovado em outubro 2020. 